\title{
Argentine Ant Affects Ant-Mimetic Arthropods: Does Argentine Ant Invasion Conserve Colouring Variation of Myrmecomorphic Jumping Spider?
}

\author{
Yoshifumi Touyama', Fuminori Ito ${ }^{2}$ \\ ${ }^{1}$ Niho, Minami-ku, Hiroshima City, Japan \\ ${ }^{2}$ Laboratory of Entomology, Faculty of Agriculture, Kagawa University, Ikenobe, Japan \\ Email: toy@s6.dion.ne.jp
}

Received 23 April 2014; revised 3 June 2014; accepted 22 June 2014

Copyright (C) 2014 by authors and Scientific Research Publishing Inc.

This work is licensed under the Creative Commons Attribution International License (CC BY).

http://creativecommons.org/licenses/by/4.0/

\section{c) (i) Open Access}

\begin{abstract}
Argentine ant invasion changed colour-polymorphic composition of ant-mimetic jumping spider Myrmarachne in southwestern Japan. In Argentine ant-free sites, most of Myrmarachne exhibited all-blackish colouration. In Argentine ant-infested sites, on the other hand, blackish morph decreased, and bicoloured (i.e. partly bright-coloured) morphs increased in dominance. Invasive Argentine ant drives away native blackish ants. Disappearance of blackish model ants supposedly led to malfunction of Batesian mimicry of Myrmarachne.
\end{abstract}

\section{Keywords}

Batesian Mimicry, Biological Invasion, Linepithema humile, Myrmecomorphy, Myrmarachne, Polymorphism

\section{Introduction}

It has attracted attention of biologists that many arthropods morphologically and/or behaviorally resemble ants [1]-[4]. Resemblance of non-ant arthropods to aggressive and/or unpalatable ants is called myrmecomorphy (ant-mimicry). Especially, spider myrmecomorphy has been described through many literatures [5]-[9]. Myrmecomorphy is considered to be an example of Batesian mimicry gaining protection from predators. Previous studies demonstrate that myrmecomorphic spiders are less likely to be preyed by predators [10]-[12]. In order to gain advantage through Batesian mimicry, ant-mimetic spiders must live in close proximity to model ants 
[13]-[15]. Disappearance of model species may consequently lead to malfunction of Batesian mimicry. Notwithstanding, few studies mentioned the effects of model ant disappearance on ant-mimics [16].

As for the causes of ant disappearance, it is notorious that invasion of exotic Argentine ant expels native ants [17]. Also in Japan, most of indigenous ants were driven away by Argentine ant [18] [19]. Ant is one of the most abundant organism in terrestrial ecosystem, and has various (hostile and symbiotic) relationships with other animals and plants [20]-[22]. Native ants' disappearance caused by Argentine ant, therefore, variously and widely affects other animals and plants [23]. In Japan, previous studies showed that Argentine ant had various relationships with non-ant animals [24]-[27]. However, little has been studied about indirect effects of Argentine ant, via the disappearance of native ants, on some predators, competitors, symbionts and myrmecomorphs. So, in present paper, we are concerned with the response of ant-mimicking jumping spider Myrmarachne against Argentine ant invasion.

\section{Materials and Methods}

\subsection{Study Taxa}

Myrmarachne (Araneae: Salticidae) is a speciose genus of jumping spiders and the most striking examples of myrmecomorphy. Spiders of Myrmarachne morphologically and behaviorally mimic ants. Some Myrmarachne species exhibit variation of dermal colouration within species (colour-polymorphic mimicry), possibly each mimicking different ant species [6] [28]-[35]. Moreover, some species of Myrmarachne show transformational mimicry, mimicking different ant species at each instar [6] [32]. In addition, many species of Myrmarachne are sexually dimorphic [36]. Such colour-polymorphism, transformational mimicry and sexual dimorphism all contribute to the difficulty of visual identification of Myrmarachne spp. on site. Furthermore, since the same-coloured "morphs" of whatever species supposedly mimic the same ant species, such "morphs", not "species", should similarly respond to myrmecofaunal change. In this study, from the viewpoint of ant-resemblance, we tentatively grouped Myrmarachne spp. by colour-morphs, regardless of sex and instar, as mentioned below.

Blackish morph. Colouration: All black, or black with blackish brown posterior cephalothorax and/or anterior abdomen (Figure 1(a) and Figure 1(b)). Posterior abdomen of some individuals grayish; Species: Typical types of M. japonica (Karsch) and M. inermichelis Bösenberg \& Strand, and blackish type of M. elongata Szombathy; Possible model ants in lowland of Hiroshima Prefecture: Camponotus japonicus Mayr (M. japonica is especially mimics this ant), Formica japonica Motschoulsky, Tetramorium tsushimae Emery, Nylanderia amia (Forel), and Ochetellus glaber (Mayr). The latter three species are candidate models of juvenile mimics. Besides, Pachycondyla chinensis (Emery) morphologically resembles M. inermichelis, but it is rarely seen on plants.

Bicoloured morphs. Partially bright coloured. Including three subtypes as mentioned below.

Front-brightened morph. Colouration: Cephalothorax and anterior abdomen bright, posterior abdomen blackish (Figure 1(c)). Bright colour varied among individuals: light brown (leather brown), strong brown (raw
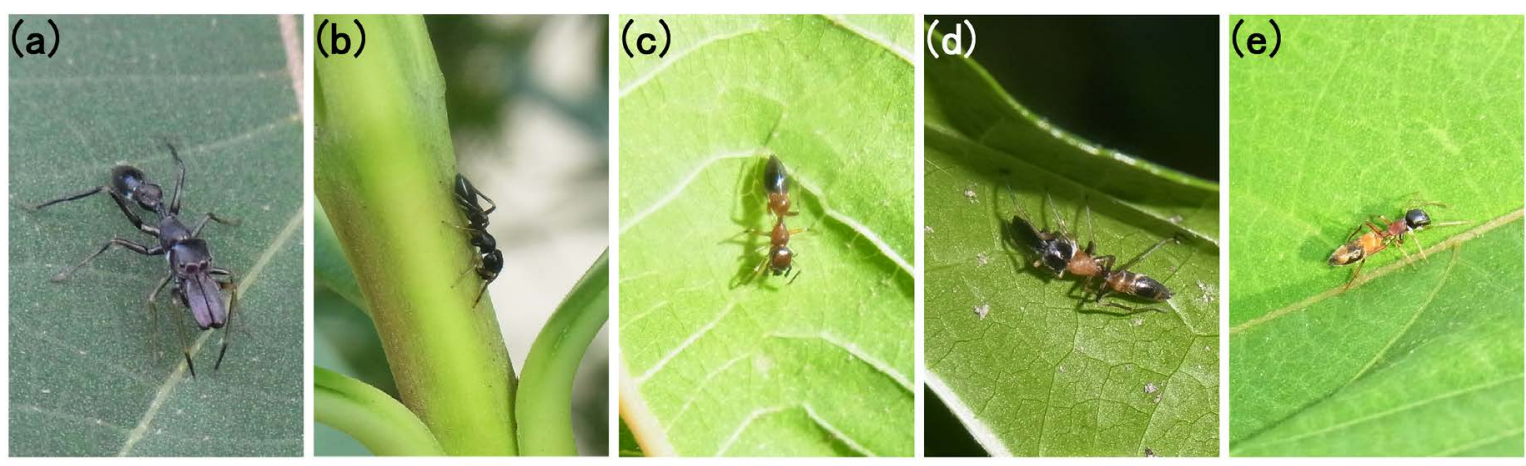

Figure 1. Typical colour-morphs of genus Myrmarachne in lowland of southwestern Japan. (a) Blackish morph (typical type of $M$. inermichelis, male); (b) Blackish morph (typical type of $M$. inermichelis, female); (c) Front-brightened morph (supposedly reddish type of $M$. inermichelis, juvenile); (d) Mid-brightened morph (typical type of M. elongata, male); (e) Mid-brightened morph (typical type of M. elongata, female). 
sienna), strong yellowish brown (khaki), moderate yellow, and so on. Bright parts do not always exhibit the same colour; Species: Reddish type of juvenile M. inermichelis [34]; Possible model ants: Monomorium intrudens F. Smith, Tetramorium bicaritatum (Nylander), and some of Camponotus vitiosus F. Smith. Although typical C. vitiosus exhibit mid-brightened colouration as mentioned below, some of $C$. vitiosus exhibit front-brightened colouration.

Mid-brightened morph. Colouration: Anterior cephalothorax and posterior abdomen blackish, posterior cephalothorax and/or anterior abdomen bright-coloured (Figure 1(d) and Figure 1(e)). Bright colour varied among individuals: light brown (leather brown), strong brown (raw sienna), strong yellowish brown (khaki), deep yellow (yellow ocher), moderate yellow, moderate red (brick red), deep red (ruby), brownish orange, and so on. Posterior cephalothorax and anterior abdomen do not always exhibit the same colour; Species: Typical type of M. elongata; Possible model ants: Typical C. vitiosus and Pheidole noda F. Smith. Although Polyrhachis lamellidens F. Smith and Camponotus hemichlaena Yasumatsu \& Brown also exhibit mid-brightened colouration, these ants are rarely seen in lowland urban/residential area of Hiroshima.

Rear-brightened morph. Colouration and species: Some of this morph have blackish cephalothorax and bright abdomen, others have bright abdomen with blackish belt at middle abdomen. The former is bright type of $M$. japonica, the latter may be M. elongata with blackish posterior cephalothorax and bright-coloured posterior abdomen. Bright colour varied among individuals: strong yellowish brown (khaki), moderate yellowish brown (buff), deep yellow (yellow ocher), and so on; Model ant: unknown.

\subsection{Study Sites and Methods}

Spider survey was conducted in lowland suburbs of Hiroshima and Fukuoka Prefectures in 2012-2013 (Figure 2): urban greenery space, roadside, vacant lot, and so on. Argentine ant-infested sites were similar to free sites in their landscape. As for ant fauna, however, indigenous ants almost disappeared from Argentine ant-infested sites. Spiders of genus Myrmarachne were visually searched on herb, shrub, tree trunk, fence, and so on. Each Myrmarachne spider seen was recorded on site, and photographed as much as possible. In 2012 survey, Myrmarachne were searched in various places in order to confirm whether Argentine ant invasion affected colour-polymorphic composition of Myrmarachne (Figure 2): five Argentine ant-free sites in Fukuoka Prefecture (August); eight free sites in Hiroshima Prefecture (August-October); and five Argentine ant-infested sites, sepa-

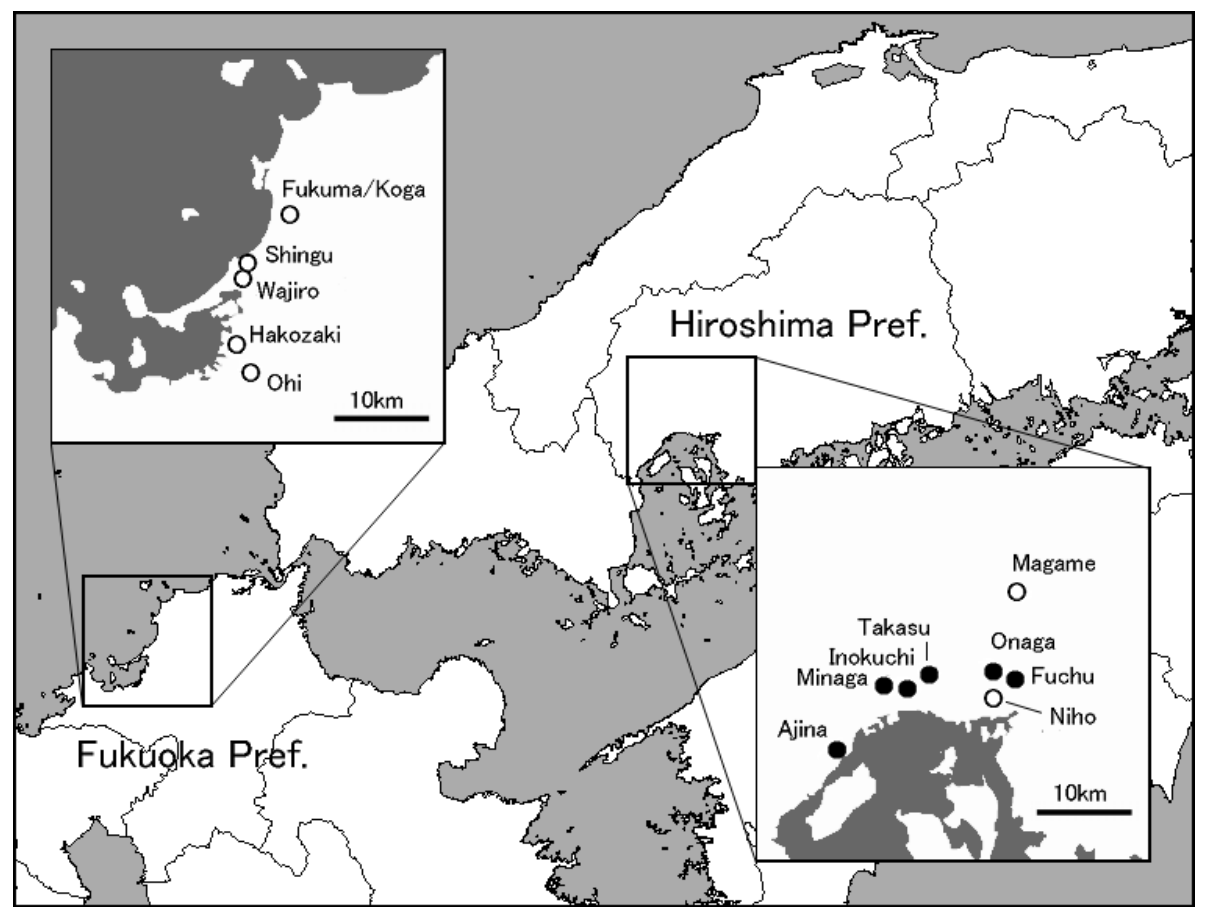

Figure 2. Location of study sites in 2012 survey. Each open circle shows Argentine ant-free site. Every closed circle includes both Argentine ant-free and infested sites. 
rately located each other, in Hiroshima Prefecture (August-October). These infested sites were already reported [37] [38]. In 2013 survey, colour-polymorphic composition was seasonally surveyed in the four successive sites of Hiroshima Prefecture: Ajina, Minaga, Inokuchi and Onaga. In November 2013, however, we could not survey in Ajina for lack of time.

\section{Results}

\subsection{Colour-Polymorphic Composition: 2012 Survey}

In the most of Argentine ant-free sites, colour-polymorphic composition showed common pattern irrespective of locality (Table 1). That is, blackish morph overwhelmingly dominated (median 85.0\%), and bicoloured morphs generally occupied less than a fifth (median 15.0\%). Among the bicoloured morphs in Argentine ant-free sites,

Table 1. Comparison of polymorphic composition of Myrmarachne spiders Across Argentine ant infestation. Figures in parenthesis show the percentages.

\begin{tabular}{llccc}
\hline \multirow{3}{*}{ Blackish } & \multicolumn{3}{c}{ Bicoloured } & \\
\cline { 3 - 4 } & & Front & Mid & Rear
\end{tabular}

Argentine ant-free

Fukuoka Prefecture

\begin{tabular}{|c|c|c|c|c|c|c|c|c|}
\hline Ohi & 4 & (66.7) & 2 & (33.3) & & & 6 & $(100.0)$ \\
\hline Hakozaki & 7 & $(87.5)$ & 1 & (12.5) & & & 8 & $(100.0)$ \\
\hline Wajiro & 6 & (37.5) & 9 & (56.3) & 1 & (6.3) & 16 & $(100.0)$ \\
\hline Shingu & 6 & $(100.0)$ & & & & & 6 & $(100.0)$ \\
\hline Fukuma/Koga & 7 & (77.8) & 2 & (22.2) & & & 9 & $(100.0)$ \\
\hline
\end{tabular}

Hiroshima Prefecture

\begin{tabular}{|c|c|c|c|c|c|c|c|c|c|c|}
\hline Ajina & 17 & $(85.0)$ & & & 3 & (15.0) & & & 20 & (100.0) \\
\hline Minaga & 13 & $(72.2)$ & & & 4 & (22.2) & 1 & (5.6) & 18 & (100.0) \\
\hline Inokuchi & 29 & (82.9) & 1 & (2.9) & 4 & (11.4) & 1 & (2.9) & 35 & (100.0) \\
\hline Takasu & 18 & (100.0) & & & & & & & 18 & (100.0) \\
\hline Magame & 10 & (90.9) & & & 1 & (9.1) & & & 11 & (100.0) \\
\hline Onaga & 17 & (68.0) & & & 7 & (28.0) & 1 & (4.0) & 25 & (100.0) \\
\hline Niho & 17 & (89.5) & & & 2 & (10.5) & & & 19 & (100.0) \\
\hline Fuchu & 12 & (92.3) & & & 1 & (7.7) & & & 13 & (100.0) \\
\hline
\end{tabular}

Argentine ant-infested

Hiroshima Prefecture

$\begin{array}{lcccccccccc}\text { Ajina } & 10 & (43.5) & 2 & (8.7) & 10 & (43.5) & 1 & (4.3) & 23 & (100.0) \\ \text { Minaga } & 8 & (44.4) & 1 & (5.6) & 9 & (50.0) & & & 18 & (100.0) \\ \text { Inokuchi } & 6 & (26.1) & & & 16 & (69.6) & 1 & (4.3) & 23 & (100.0) \\ \text { Takasu } & 10 & (55.6) & 2 & (11.1) & 6 & (33.3) & & & 18 & (100.0) \\ \text { Onaga } & 10 & (55.6) & 2 & (11.1) & 6 & (33.3) & & & 18 & (100.0) \\ \text { Fuchu } & 6 & (46.2) & 1 & (7.7) & 4 & (30.8) & 2 & (15.4) & 13 & (100.0)\end{array}$


mid-brightened morph was almost ubiquitous, but generally less than a fifth yet (median 12.5\%). In Argentine ant-infested sites, on the other hand, blackish morph decreased in dominance than in free sites (median, from $85.0 \%$ to $45.3 \%$ ), and bicoloured morphs increased to the majority in return (median, from $15.0 \%$ to $54.8 \%$ ); especially mid-brightened morph conspicuously increased than in free sites (median, from $12.5 \%$ to $38.4 \%$ ). Besides, front-brightened morph was almost limited in Argentine ant-infested sites. Mann-Whitney U-test showed that morphic dominance were significantly different between Argentine ant-free and infested sites (blackish morph, $\mathrm{p}=0.0029$; front-brightened morph, $\mathrm{p}=0.0050$; mid-brightened morph, $\mathrm{p}=0.0050$ ), excluding rearbrightened morph $(p=0.4048)$. Across the prefectures in Argentine ant-free sites, on the other hand, there were no differences of colour-polymorphic dominance (blackish morph, $\mathrm{p}=0.3414$; front-brightened morph, $\mathrm{p}=$ 0.7144; mid-brightened morph, $\mathrm{p}=0.2416$; rear-brightened morph, $\mathrm{p}=0.7697$; Mann-Whitney U-test).

\subsection{Seasonal Change: 2012-2013 Survey}

Morphic composition in 2013 survey generally showed the same pattern as in 2012 (Table 2). Wilcoxon signedranks tests, by matching of simultaneous data between Argentine ant-free and infested sites (Ajina, Minaga, Inokuchi and Onaga), also showed that morphic dominance (\%) were significantly different between free and infested sites (blackish morph, $\mathrm{p}=0.0003$; front-brightened morph, $\mathrm{p}=0.0455$; mid-brightened morph, $\mathrm{p}=$ $0.0005)$, excluding rear-brightened morph $(p=0.4497)$. However, there were common patterns in seasonal fluctuation of colour-polymorphic composition to Argentine ant-free and infested sites. That is, bicoloured morphs increased in summer regardless of Argentine ant infestation; blackish morph accordingly decreased in dominance then. In Argentine ant-free sites after summer, blackish morph always recovered and gained the overwhelming majority (median 85.0\%), but bicoloured morphs almost disappeared. In Argentine ant-infested sites, on the contrary, bicoloured morphs had always stated on, in spite of decrease after summer; and blackish morph repeatedly lost the majority (median 50.0\%), despite of dominating just before summer.

Table 2. Comparison of seasonal change of polymorphic composition of Myrmarachne spiders across Argentine ant infestation. Figures in parenthesis show the percentages.

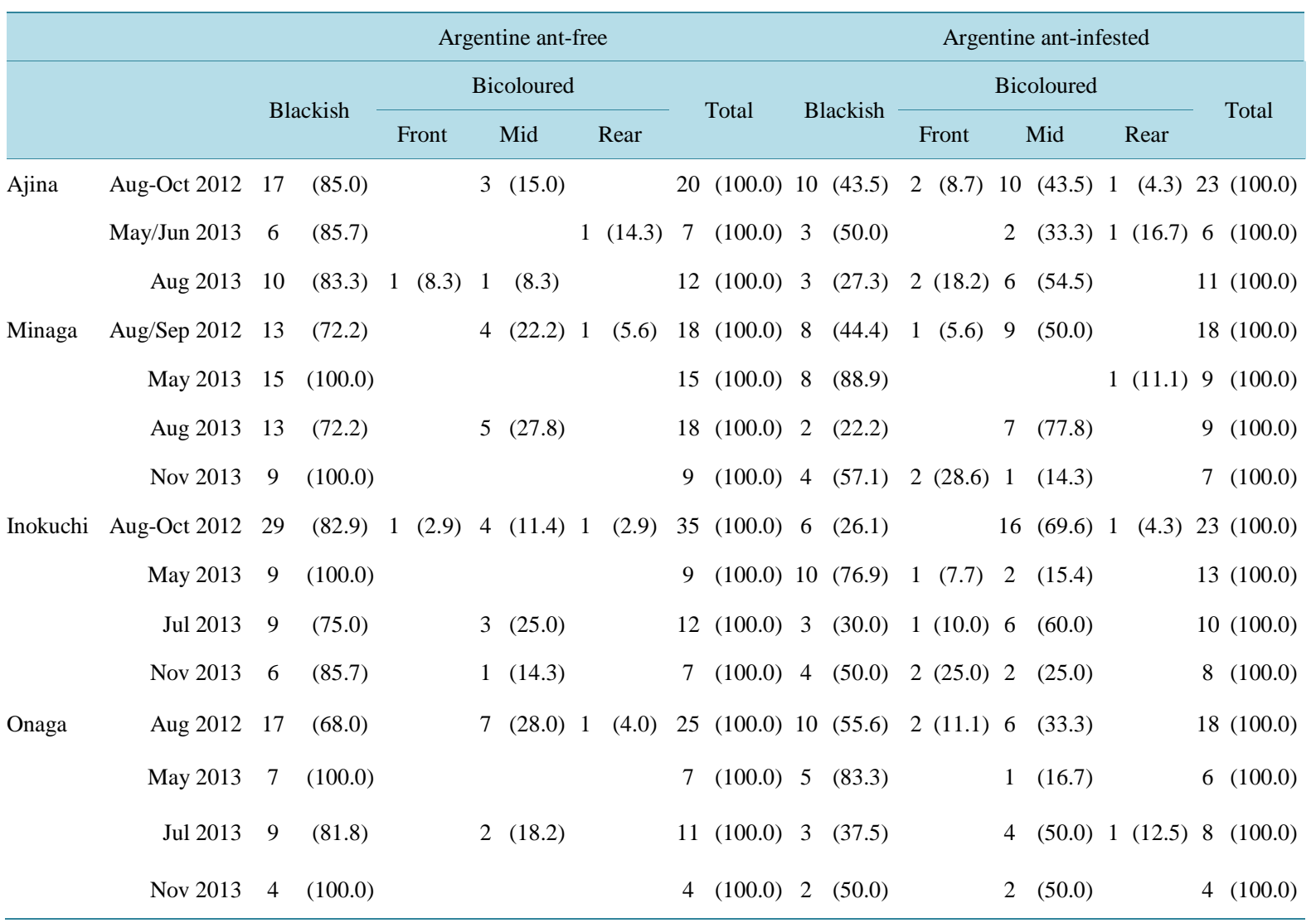




\section{Discussion}

In lowland urban/residential area of Hiroshima Prefecture, blackish ants (e.g. F. japonica and C. japonicus) are more prevailing in dominance than bicoloured ant C. vitiosus [18] [19]. It may be the reason why blackish morph gains the majority in Argentine ant-free sites. However, such oligopoly of blackish morph was weakened, i.e. bicoloured morphs increased, in summer. What caused summer increase and afterward decrease of bicoloured morphs in dominance? Those that M. elongata (i.e. the majority of bicoloured morphs) hatched earlier and $M$. inermichelis (the majority of blackish morph) did later can account for this pattern. Instead of later hatching of M. inermichelis, after-summer increase of predator of bicoloured Myrmarachne may lead similar pattern. Whatever led such seasonal fluctuation, this pattern was common to Argentine ant-infested and free sites. That is, Argentine ant invasion did not affect the occurrence of such fluctuation itself. Here, we would like to emphasize the difference of the polymorphic dominance between infested and free sites. What kept the dominance of bicoloured morphs higher in infested sites than free sites? In other words, what prevented blackish morph to gain the majority in Argentine ant-infested sites after summer?

Precondition for Batesian mimicry is that mimic lives in close proximity to model. Disappearance of model species should consequently cause malfunction of Batesian mimicry. Piñol et al. (2012) showed that long-term exclusion of ant led decrease of ant-mimetic mirid bug [16]. Disappearance of indigenous ants caused by Argentine ant may similarly work on myrmecomorphic Myrmarachne spiders. Correspondingly, ant-mimetic mirid bugs decreased in Argentine ant-infested sites in Japan (Touyama \& Ito, in preparation).

Blackish morph of Japanese Myrmarachne, dominating in Argentine ant-free sites, mainly resembles native ants $F$. japonica and $C$. japonicus. Such ant species disappear from Argentine ant-infested sites, in spite of ubiquity and dominating in Argentine ant-free sites [18] [19]. Disappearance of model ants (F. japonica and C. japonicus) supposedly led to decrease of their mimics, i.e. blackish morph of Myrmarachne spiders, in infested sites via invalidation of Batesian mimicry. Bicoloured morphs of Myrmarachne spiders, on the other hand, resemble some bicoloured ant species. Front-brightened morph resembles C. vitiosus (with non-typical colouration), T. bicarinatum, and $M$. intrudens (candidate model of juvenile mimics). Mid-brightened morph may mimic C. vitiosus (with typical colouration) and/or P. noda in urban/residential area of lowland Hiroshima. Among such potential model ants, C. vitiosus is ubiquitous through urban/residential area of lowland Hiroshima, and relatively resistant against Argentine ant invasion [18] [19]. The existence of bicoloured C. vitiosus in infested sites possibly provides some advantage for bicoloured morphs of Myrmarachne.

It seems plausible to suppose that Argentine ant-inducing myrmecofaunal change caused the change of colour-polymorphic composition of ant-mimetic Myrmarachne. As for ant-mimicking bug (Hemiptera: Alydidae), Oliveira (1985) pointed out that colour-polymorphic composition was changed with myrmecofaunal composition [39]. Regrettably, present study was not concerned with quantitative comparison of Myrmarachne across Argentine ant infestation. But our previous study suggested that there were no difference of density and incidence of total Myrmarachne on shrub Mallotus japonicus between Argentine ant-free and infested sites (Touyama \& Ito, in preparation).

Unidentified predators of Myrmarachne (i.e. operator of ant-mimicry) should suffer little effect by Argentine ant infestation, if the change of colour-polymorphic composition was due to the invalidation of Batesian mimicry. We did not regrettably come across any scenes of Myrmarachne preyed by whatever predator throughout the present study. We have repeatedly, but not quantitatively, observed some predatory arthropods in Argentine ant-infested sites as well as free sites (Touyama unpublished data, 2012-2013): crab spider (Araneae: Thomisidae), lynx spider (Araneae: Oxyopidae), jumping spider, and mantises (Mantodea: Mantidae). Among them, mantis [11], Salticidae and Philodromidae spiders [10] were suggested to be important predators of non-mimetic spiders, and be deceived by Batesian mimicry. We have not seen Philodromid spider during present study, but repeatedly observed crab spiders (Araneae: Thomisidae) which have similar life form (sit-and-wait predator) as Philodromidae. But we doubt whether crab spiders is deceived by myrmecomorphy, based on the following two circumstantial evidences. First, McIver (1987) pointed out that crab spider could properly discriminate between model ants and mimicking mirid bug [40]. Secondly, some crab spiders preferingly predate, rather than evade, ants [41]: we have observed some crab spider preying native black ant $F$. japonica in three cases (Ajina in 8 October 2012 and 25 May 2013; Inokuchi in 16 May 2013: all in free sites). Incidentally, we have come across no scenes of Argentine ant preyed by whatever predator. Besides the Batesian mimicry, there is a little ironical hypothesis that myrmecophagic Thomicid spider (and/or other predator) may become prey on blackish morph of 
Myrmarachne, instead of the disappeared black ants. But we have no data concerning this story. This problem needs further study.

In examination of ecological problems caused by Argentine ant, we are likely to be attracted to direct charge and/or harassment, rather than indirect effects via native ant disappearance, by Argentine ant. Although it may be less attractive, indirect effects of Argentine ants invasion are ecologically worth consideration. Taking the indirect effects into account, Argentine ant may harmfully affect more organism than our awareness. It needs further investigations for right understanding of the effects of Argentine ant invasion.

\section{References}

[1] Wickler, W. (1968) Mimicry in Plants and Animals. George Weidenfeld and Nicholson Ltd., London.

[2] Rettenmeyer, C.W. (1970) Insect Mimicry. Annual Review of Entomology, 15, 43-74. http://dx.doi.org/10.1146/annurev.en.15.010170.000355

[3] McIver, J.D. and Stonedahl, G. (1993) Myrmecomorphy: Morphological and Behavioral Mimicry of ants. Annual Review of Entomology, 38, 351-379. http://dx.doi.org/10.1146/annurev.en.38.010193.002031

[4] Joron, M. (2003) Mimicry. In: Cardé, R.T. and Resh, V.H., Eds., Encyclopedia of Insects, Academic Press, New York, 714-726.

[5] Pocock, R.I. (1909) Mimicry in Spiders. Zoological Journal of the Linnean Society, 30, 256-270. http://dx.doi.org/10.1111/j.1096-3642.1909.tb02405.x

[6] Cushing, P.E. (1997) Myrmecomorphy and Myrmecophily in Spiders: A Review. Florida Entomologist, 80, 165-193. http://dx.doi.org/10.2307/3495552

[7] Cushing, P.E. (2012) Spider-Ant Associations: An Updated Review of Myrmecomorphy, Myrmecophily, and Myrmecophagy in Spiders. Psyche, 2012, Article ID: 151989.

[8] Jackson, R.R. and Nelson, X.J. (2012) Specialized Exploitation of Ants (Hymenoptera: Formicidae) by Spiders (Araneae). Myrmecological News, 17, 33-49.

[9] Ceccarelli, F.S. (2013) Ant-Mimicking Spiders: Strategies for Living with Social Insects. Psyche, 2013, Article ID: 839181.

[10] Cutler, B. (1991) Reduced Predation on the Antlike Jumping Spider Synageles occidentalis (Araneae: Salticidae). Journal of Insect Behavior, 4, 401-407. http://dx.doi.org/10.1007/BF01048287

[11] Nelson, X.J., Jackson, R.R., Li, D., Barrion, A.T. and Edwards, G.B. (2006) Innate Aversion to Ants (Hymenoptera: Formicidae) and Ant Mimics: Experimental Findings from Mantises (Mantodae). Biological Journal of the Linnean Society, 88, 23-32. http://dx.doi.org/10.1111/j.1095-8312.2006.00598.x

[12] Durkee, C.A., Weiss, M.R. and Uma, D.B. (2011) Ant Mimicry Lessens Predation on a North American Jumping Spider by Larger Salticid Spiders. Environmental Entomology, 40, 1223-1231. http://dx.doi.org/10.1603/EN11057

[13] Oliveira, P.S. (1988) Ant-Mimicry in Some Brazilian Salticid and Clubionid Spiders (Aranea: Salticidae, Clubionidae). Biological Journal of the Linnean Society, 33, 1-15. http://dx.doi.org/10.1111/j.1095-8312.1988.tb00443.x

[14] Nelson, X.J., Jackson, R.R., Edwards, G.B. and Barrion, A.T. (2005) Living with the Enemy: Jumping Spiders that Mimic Weaver Ants. The Journal of Arachnology, 33, 813-819. http://dx.doi.org/10.1636/S04-12.1

[15] Edmunds, M. (2006) Do Malaysian Myrmarachne Associate with Particular Species of Ant? Biological Journal of the Linnean Society, 88, 645-653. http://dx.doi.org/10.1111/j.1095-8312.2006.00649.x

[16] Piñol, J., Ribes, E., Ribes, J. and Espadaler, X. (2012) Long-Term Changes and Ant-Exclusion Effects on the True Bugs (Hemiptera: Heteroptera) of an Organic Citrus Grove. Agriculture, Ecosystem and Environment, 158, 127-131. http://dx.doi.org/10.1016/j.agee.2012.06.004

[17] Holway, D.A., Lach, L., Suarez, A.V., Tsutsui, N.D. and Case, T.J. (2002) The Causes and Consequences of Ant Invasions. Annual Review of Ecology and Systematics, 33, 181-233. http://dx.doi.org/10.1146/annurev.ecolsys.33.010802.150444

[18] Miyake, K., Kameyama, T., Sugiyama, T. and Ito, F. (2002) Effect of Argentine Ant Invasions on Japan: A Preliminary Report (Hymenoptera: Formicidae). Sociobiology, 39, 1-10.

[19] Touyama, Y., Ogata, K. and Sugiyama, T. (2003) The Argentine Ant, Linepithema humile, in Japan: Assessment of Impact on Species Diversity of Ant Communities in Urban Environments. Entomological Science, 6, 57-62. http://dx.doi.org/10.1046/j.1343-8786.2003.00008.x

[20] Hölldobler, B. and Wilson, E.O. (1990) The Ants. Belknap Press of Harvard University Press, Cambridge, 732 p.

[21] Schultz, T.R. and McGlynn, T. (2000) The Interaction of Ants with Other Organisms. In: Agosti, D., Majer, J.D., 
Alonso, L.E. and Schultz, T.R., Eds., Ants: Standard Methods for Measuring and Monitoring Biodiversity, Smithsonian Institute Press, New York, 35-44.

[22] Terayama, M. and Maruyama, M. (2007) A Preliminarily List of the Myrmecophiles in Japan. ARI, 30, 1-37. (in Japanese)

[23] Ness, J.H. and Bronstein, J.L. (2004) The Effects of Invasive Ants on Prospective Ant Mutualists. Biological Invasions, 6, 445-461. http://dx.doi.org/10.1023/B:BINV.0000041556.88920.dd

[24] Terayama, M., Tanaka, Y. and Tatsuki, S. (2006) Effects of the Invasive Ants Linepithema humile (Hymenoptera: Formicidae) on Native Ant and Homopterous Insect Communities in Japan. ARI, 28, 13-27. (in Japanese with English Abstract)

[25] Touyama, Y., Ihara, Y. and Ito, F. (2008) Argentine Ant Infestation Affects the Abundance of Native Myrmecophagic Jumping Spider Siler cupreus Simon in Japan. Insectes Sociaux, 55, 144-146. http://dx.doi.org/10.1007/s00040-008-0983-8

[26] Ito, F., Okaue, M. and Ichikawa, T. (2009) A Note on Prey Composition of the Japanese Treefrog, Hyla japonica, in an Area Invaded by Argentine Ants, Linepithema humile, in Hiroshima Prefecture, Western Japan (Hymenoptera: Formicidae). Myrmecological News, 12, 35-39.

[27] Touyama, Y. and Ito, F. (2013) Neither the Fable’s nor Fabre’s Description of “Cicada and Ants” Agree with Argentine Ant Behaviour in Japan. ARI, 35, 6-14. (in Japanese with English Abstract)

[28] Yaginuma, T. (1986) Spiders of Japan in Color: New Edition. Hoikusha Publishing Co. Ltd., Osaka, 305 p. (in Japanese)

[29] Borges, R.M., Ahmed, S. and Prabhu, C.V. (2007) Male Ant-Mimicking Salticid Spiders Discriminate between Retreat Silks of Sympatric Females: Implications for Pre-Mating Reproductive Isolation. Journal of Insect Behavior, 20, 389402. http://dx.doi.org/10.1007/s10905-007-9085-0

[30] Ceccarelli, F.S. and Crozier, R.H. (2007) Dynamics of the Evolution of Batesian Mimicry: Molecular Phylogenetic Analysis of Ant-Mimicking Myrmarachne (Aranea: Salticidae) Species and Their Ant Models. Journal of Evolutional Biology, 20, 286-295. http://dx.doi.org/10.1111/j.1420-9101.2006.01199.x

[31] Chikuni, Y. (2008) Pictorial Encyclopedia of Spiders in Japan. Revised Edition, Kaisei-Sha Publishing, Co. Ltd., Tokyo, 308 p. (in Japanese)

[32] Ceccarelli, F.S. (2010) New Species of Ant-Mimicking Jumping Spiders of the Genus Myrmarachne MacLeay, 1839 (Araneae: Salticidae) from North Queenssland, Australia. Australian Journal of Entomology, 49, 245-255. http://dx.doi.org/10.1111/j.1440-6055.2010.00756.x

[33] Nelson, X.J. (2010) Polymorphism in an Ant Mimicking Jumping Spider. The Journal of Arachnology, 38, $139-141$. http://dx.doi.org/10.1636/Hi09-36.1

[34] Shouji, K. (2011) Spiders around Koremasa Bridge of Tama River. KISHIDAIA, 99, 45-53. (in Japanese. Title was Conveniently Translated into English by Authors)

[35] Hashimoto, Y. (2013) Are There Associations between Ant-Mimicking Spider and Ant Diversity in Tropical Forests? The Nature and Insects, 48, 7-10. (in Japanese)

[36] Wanless, F.R. (1978) A Revision of the Spider Genera Belippo and Myrmarachne (Araneae: Salticidae) in the Ethiopian Region. Bulletin of the British Museum (Natural History), Zoology Series, 33, 1-139.

[37] Okaue, M., Yamamoto, K., Touyama, Y., Kameyama, T., Terayama, M., Sugiyama, T., Murakami, K. and Ito, F. (2007) Distribution of the Argentine Ant, Linepithema humile, along the Seto Inland Sea, Western Japan: Result of Surveys in 2003-2005. Entomological Science, 10, 337-342. http://dx.doi.org/10.1111/j.1479-8298.2007.00228.x

[38] Touyama, Y. (2008) Recent Report of the Argentine Ant Invasion in Hiroshima City in 2007. ARI, 31, 33-39. (in Japanese with English Abstract)

[39] Oliveira, P.S. (1985) On the Mimetic Association between Nymphs of Hyalymenus spp. (Hemiptera: Alydidae) and Ants. Zoological Journal of the Linnean Society, 83, 371-384. http://dx.doi.org/10.1111/j.1096-3642.1985.tb01182.x

[40] McIver, J.D. (1987) On the Myrmecomorph Coquillettia insignis Uhler (Hemiptera: Miridae): Arthropod Predators as Operators in an Ant-Mimetic System. Zoological Journal of the Linnean Society, 90, 133-144. (in Japanese) http://dx.doi.org/10.1111/j.1096-3642.1987.tb01352.x

[41] Shinkai, E. (2006) Spiders of Japan. Bun-Ichi Sogo Shuppan, Tokyo, 335 p. (in Japanese) 
Scientific Research Publishing (SCIRP) is one of the largest Open Access journal publishers. It is currently publishing more than 200 open access, online, peer-reviewed journals covering a wide range of academic disciplines. SCIRP serves the worldwide academic communities and contributes to the progress and application of science with its publication.

Other selected journals from SCIRP are listed as below. Submit your manuscript to us via either submit@scirp.org or Online Submission Portal.
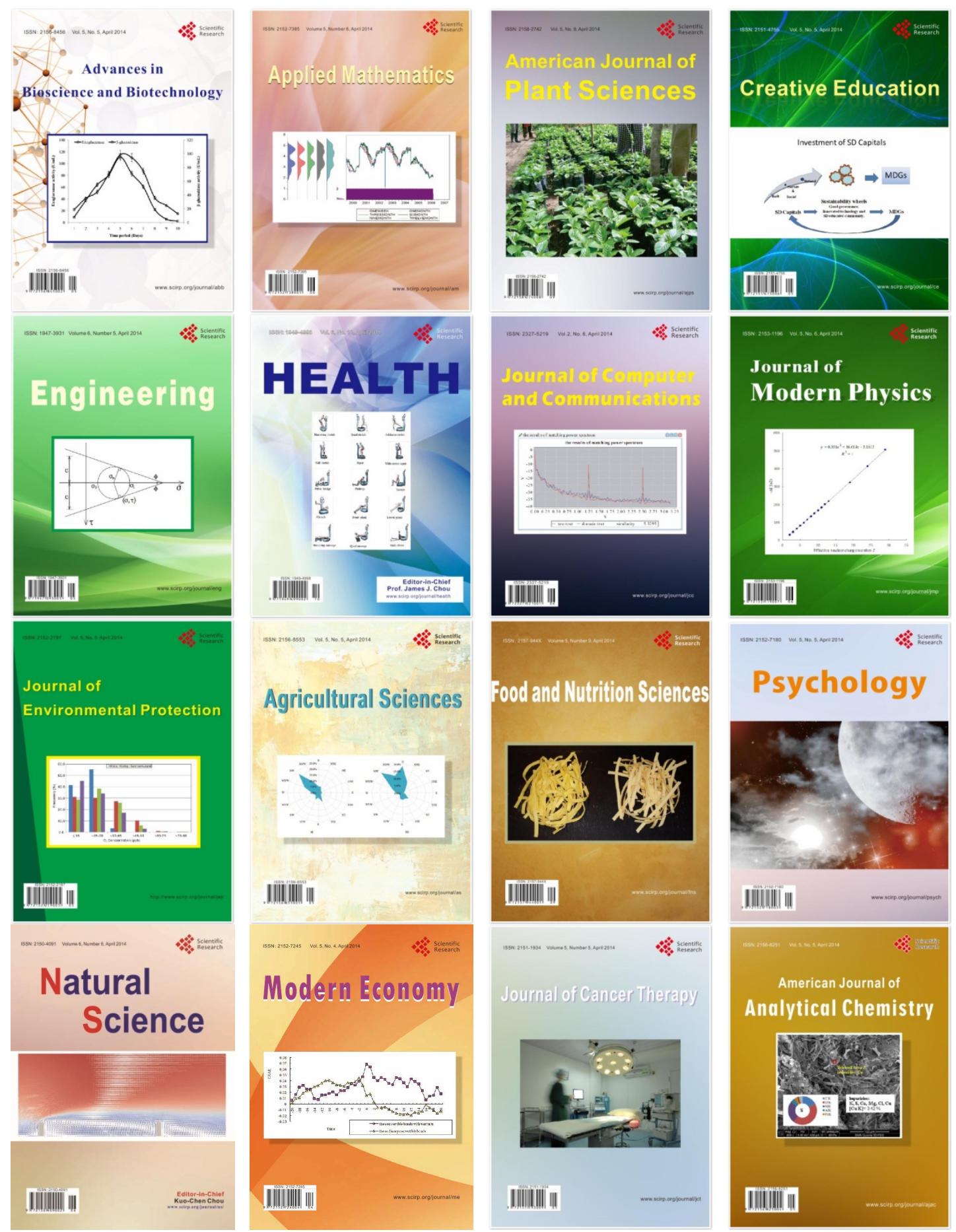